Revista Complutense de Historia de América

ISSN: 1132-8312

http://dx.doi.org/10.5209/RCHA.56724

\title{
Debates y consensos en torno a la corrupción en la América hispana y portuguesa, siglos XVI-XVIII. Presentación ${ }^{1}$
}

Pilar Ponce Leiva ${ }^{2}$

El presente dossier forma parte del proyecto de investigación Entre venalidad y corrupción en la Monarquía Hispánica durante el Antiguo Régimen, en el seno del cual se han realizado diferentes seminarios y publicaciones sobre el tema específico de corrupción. Una de las últimas actividades en este marco ha sido el congreso "Debates sobre la corrupción en el Mundo Ibérico, siglos XVI-XVIII", celebrado en Madrid los días 8 y 9 de mayo de 2017 con la asistencia de más de 80 investigadores procedentes de 10 países de Europa y América Latina, lo cual es un claro indicador del creciente interés suscitado por ese tema.

Al ser la corrupción un campo de estudio consolidado en el americanismo, con una sólida tradición analítica al menos desde la década de 1980, llama la atención su escasa implantación tanto en la península Ibérica como en el espacio brasileño. En la historiografía modernista europea (más concretamente española), la potencia del patrocinio cortesano y las relaciones de parentesco y patronazgo, así como el carácter funcionalista de la corrupción en el sistema económico, cuestionaron durante años la posibilidad de emplear dicho término (sin comillas) en el análisis histórico correspondiente a los siglos XVI-XVIII. Entendemos que hoy la perspectiva es diferente.

Como muy bien han señalado diferentes colegas, el análisis de la corrupción va más allá de los escándalos que impactaron al público por el monto de los fraudes cometidos o por el daño causado a la comunidad política ${ }^{3}$. No es suficiente con abordar el tema desde una perspectiva estrictamente descriptiva; interesa sobre todo aprovechar su potencial analítico, pues sintetiza y unifica diversos aspectos comunes a las diferentes nociones de corrupción ${ }^{4}$.

En la última década se ha producido una eclosión de ejes temáticos y planteamientos en esta materia, que implican tanto su vertiente teórica como práctica y metodológica: al dia de hoy, interesa alcanzar una definición amplia, flexible y con-

\footnotetext{
Proyecto I+D HAR2014-55305-P, financiado por el Ministerio de Economía y Competitividad (España). Versiones preliminares de los textos firmados por Andújar Castillo y Ponce Leiva incluidos en este dossier fueron presentadas en el Seminario Corrupción y anticorrupción en la Monarquía Hispánica. Fuentes, prácticas y debates, celebrado en la Escuela Española de Historia y Arqueología en Roma - CSIC en junio de 2016. Sobre la misma temática y proyecto véase Ponce Leiva - Andújar Castillo, 2016; Andújar - Feros - Ponce (en prensa); Gil - Villarreal (en prensa).

2 Universidad Complutense de Madrid (España)

E-mail: piponce@ucm.es

3 Ruderer - Rosenmüller, 2016: 15.

4 Gil Martínez (en prensa)
} 
sensuada del concepto, pero también la percepción que los coetáneos tenían del fenómeno, las vías por las cuales transitaban las prácticas corruptas, la magnitud de los fraudes cometidos, los mecanismos de control implantados por las monarquías ibéricas para limitar su impacto o, las fuentes documentales a disposición del investigador que quiera aproximarse a unas actividades que por naturaleza fueron secretas. Tales son algunas de las cuestiones abordadas en este dossier.

Superadas las barreras historiográficas largamente sostenidas entre los diferentes espacios ibéricos, se presentan a continuación textos referidos a Castilla, Chile, Quito y Brasil. La mayor parte de ellos ponen de manifiesto, además, la circulación de agentes a lo largo y ancho de las monarquías ibéricas, conectado espacios tan diversos y lejanos como la India y Castilla, o como Brasil, Quito, Panamá, Santiago de Chile y Madrid cuyas historias se ven entrelazadas por la presencia ubicua de la corrupción.

No cabe duda de que los hechos corruptos hay que considerarlos como parte de la realidad global, que existen en todas las épocas y regiones ${ }^{5}$, pero a la vez resultan incomprensibles si no quedan debidamente insertados en el contexto en el cual se producen. El concepto mismo de "corrupción" presenta un carácter polisémico, al depender en gran medida de los contextos espacial, temporal y temático (o contexto de uso) en el que se analice ${ }^{6}$. Si el contexto de uso obliga a diferenciar materias, géneros y discursos diferentes -ya que de no hacerlo se corre el riesgo de unificar bajo un mismo nombre cosas distintas (o que reciben tratamientos distintos)-, resulta imprescindible atender tanto al contexto en el cual se producen aquellas prácticas sociales que derivan en corrupción -que provocan la "enfermedad" del cuerpo social-, como al contexto preciso en el cual esas prácticas son consideradas "excesos": es el contexto el que determina la condición de "exceso", y no la condición de "exceso" lo que define a la corrupción.

La estrecha relación entre concepto y contexto es presentada por Carlos Garriga en el ámbito jurídico a través del llamado crimen corruptionis en la cultura del ius commune. Al diferenciar claramente las dos personas que convergían en un magistrado, "la 'persona privada', que resultaba del conglomerado de situaciones carentes de relevancia política que definían su posición social y, la 'persona pública', por dotada jurisdicción, es decir, de una porción de potestad pública que le facultaba para declarar por sí el derecho e imponer coactivamente sus decisiones", Garriga aborda uno de los puntos nucleares de la historiografía sobre corrupción (o sobre no-corrupción) cual es el de la diferenciación entre lo público y lo privado en el ámbito político-administrativo del Antiguo Régimen. La conclusión al respecto no puede ser más clara: "todo el régimen del oficio (es decir, el ejercicio de la jurisdicción) se levantaba sobre la tajante separación entre ambas 'personas', tan imposible de alcanzar como imprescindible de pretender". La frontera -que no límite- entre lo público y lo privado que tantos debates ha generado entre historiadores, parece tener en el campo jurídico una resolución más sosegada. Carlos Garriga presenta, además, la existencia de un interesante y sutil debate en torno a la diferenciación entre "corrupción activa" (concusión) y "corrupción pasiva" (baratería), entre "corrupción del juez" por codicia, amor, odio o temor (baratería), y "corrupción de la justicia" (cohecho), cuestiones éstas que para el no versado en materia legal sólo resultan evidentes tras la explicación recibida.

Ruderer - Rosenmüller, 2016: 16.

Véanse al respecto los textos de Garriga y Ponce Leiva incluidos en este dossier. 
Como señala Francisco Andújar Castillo, "en materia de corrupción es evidente el predominio del estudio del caso individual, probablemente el único posible, dada la complejidad de la tarea investigadora". De ahí se deriva la clara tendencia hacia los estudios de caso -individuales o colectivos- presente en cuatro de los cinco artículos que integran el dossier; tales casos no son meras descripciones o narraciones de un conjunto de hechos, sino análisis microhistóricos de procesos de larga duración que permiten ejemplificar las ideas y las propuestas de análisis presentadas. Aún está por dilucidar -como ocurre en cualquier otra temática y disciplina- si la acumulación de estudios de caso permite llegar a conclusiones más generales sobre tendencias dominantes o, si su utilidad queda limitada por la excepcionalidad de los fenómenos. A este respecto, quizás el mayor riesgo que se corre es el de presentar la historia de la Monarquía Hispánica como una sucesión ininterrumpida de actos de corrupción debido, precisamente, a la abundancia de casos estudiados; lo cual sería tan engañoso como pretender explicar el todo por algunas de sus partes.

Desde un planteamiento metodológico Francisco Andújar pone de manifiesto la importancia del cruce de fuentes, máxime en casos de gran complejidad y ausencia de información explícita como suelen ser los de corrupción. Con gran conocimiento de los depósitos documentales españoles, Andújar evidencia el contraste existente entre fuentes oficiales -es decir, aquellas derivadas de la acción judicial o de los mecanismos de control implantados desde la administración- y la documentación privada, contraste que puede cambiar radicalmente la interpretación de un caso concreto.

Cruzando fuentes públicas y privadas de Quito, Bogotá, Lima y Madrid, la aportación de Pilar Ponce Leiva centra su atención en tres aspectos: la importancia de la corrupción como fenómeno social, el interés de las trayectorias personales como ejemplos de vidas y contextos con valor intrínseco y, la ambivalente eficacia de los mecanismos de control implantados desde la administración. Si bien la mayoría de los estudios realizados sobre la materia que nos ocupa (incluidos los de este dossier) centra su atención en el ámbito político-administrativo, Ponce Leiva aboga por considerar la corrupción como un fenómeno social que implica a estratos de muy diversa condición, que operan al margen de cualquier institución administrativa y bajo múltiples y variopintas motivaciones. En este sentido, cabe considerar que el daño económico y moral que a largo plazo infringen al cuerpo social esas prácticas cotidianas que derivan en actos de corrupción, imperceptibles a escala micro, puede ser infinitamente mayor que los grandes desfalcos llevados a cabo en los casos más conocidos: como ya sentenció el Arte de Furtar en 1652 "tomando pouco se rouba mais que tomando muito" . El gran problema que presentan los casos más escandalosos es el de su enorme toxicidad y el más que probable peligro de contagio: nada parece más alentador para cometer actos de corrupción que verlos cometer alrededor. De ahí la insistencia de los moralistas del siglo XVII en la necesidad de comportamientos virtuosos: no serán los castigos los que acaben con la corrupción, sino el ejemplo ${ }^{8}$.

Como puede comprobarse en las referencias aportadas por Maria Fernanda Bicalho, no sólo tratados políticos sino cartas, sermones y sátiras circularon por el imperio portugués denunciando las más variadas prácticas que desembocaban en la corrupción del cuerpo social. El ya citado Arte de Furtar recoge explícitamente esta

Anónimo [Manuel da Costa], 1991 [1652], cap. VII. Cita sacada de Gil Martínez (en prensa).

Ponce, 2007; Villarreal (en prensa). 
interpretación al afirmar, "Esta sarna ou tinha, que pelas mãos se pega, é tão vulgar que não há pessoa, por ignorante que seja, que não saiba pagar-se destrissimamente por sua mão, até em coisas muito leves..." . Esta obra pone de manifiesto la importancia de conocer y contextualizar adecuadamente la valoración que del fenómeno hacían los coetáneos; las causas a las que atribuían el fenómeno y sus efectos más perniciosos. Teniendo en cuenta los pocos estudios dedicados a la corrupción en el ámbito luso-brasileño, son de gran interés las obras mencionadas por Bicalho ya que permiten conocer el tratamiento dado a este tema en partes tan distantes como Goa, Maranhao o Lisboa.

Entre los diferentes mecanismos de control implantados por las monarquías ibéricas en sus dominios, la posibilidad y el derecho que tenía cualquier súbdito de recurrir bien a la justicia inmediata, bien directamente al rey -por vía de sus Consejos- fue posiblemente el instrumento más poderoso en la lucha contra la corrupción, sobrepasando en frecuencia e impacto a las conocidas visitas y residencias. Tanto Ponce como Bicalho toman como punto de partida en sus estudios sendas peticiones de amparo elevadas a la justicia por individuos que -fundada o infundadamenteconsideraron que sus derechos habían sido vulnerados por uno o varios agentes de la administración. Al margen de la motivación y resultado final de tales reclamaciones -muy diferentes en los casos analizados- el interés se centra en su mera existencia y en su condición de arma de doble filo; si por un lado quizás fuera esa la vía más eficaz para neutralizar la siempre presente y mentada distancia física entre el rey -como fuente de justicia- y los súbditos, no puede olvidarse el posible -y frecuenteuso instrumental de la acusación de corrupción para combatir al enemigo político o personal.

Por último, cabe recordar que la corrupción es un fenómeno que requiere complicidad, ya que difícilmente puede practicarse en solitario: de ahí la necesidad de rastrear y definir los vínculos interpersonales en la creación y mantenimiento de las tramas de corrupción, como puede observarse en los textos de Andújar, Ponce y Rodríguez. De todos ellos, es Antonio Rodríguez Ridao quien con más detenimiento perfila la naturaleza de las relaciones mantenidas entre los individuos implicados en el caso analizado, la sustancia que fluye entre ellas y las consecuencias que tuvieron tales relaciones en el contexto en el cual se produjeron. En la figura del gobernador de Chile Tomás Marín de Poveda, convergen temáticas esenciales para el estudio de la corrupción, como pueden ser el patrocinio familiar, la venalidad de los cargos públicos, el manejo de las finanzas reales, el trasvase de fondos de un sector económico a otro, etc.; elementos éstos que, si bien no eran intrínsecamente perjudiciales para el bien público, sí pudieron llegar a serlo por el uso que de ellos se hizo.

Con esto cerramos la presentación del presente dossier, pero aún estamos lejos de llegar a conclusiones definitivas. Los miembros de este equipo seguimos haciéndonos preguntas y compartiendo dudas, porque pensamos que es la mejor forma de investigar, de manera que si alguien tuviera alguna sugerencia sobre el tema, no tiene más que escribirnos.

Anónimo [Manuel da Costa], 1991 [1652], cap. VI. Cita sacada de Gil Martínez (en prensa). 


\section{Referencias bibliográficas}

Andújar, Francisco - Feros, Antonio - Ponce, Pilar. "A Sick Body: Corruption and Anticorruption in Early Modern Spain”. En Anticorruption in History: From Antiquity to the Modern, editado por Kroeze, Ronald - Vitória, André - Geltner, Guy. Oxford: Oxford University Press. (En prensa).

Anónimo [Manuel da Costa]. Arte de Furtar [1652], edição crítica, introdução e notas de Bismut, Roger. Lisboa: Imprensa Nacional - Casa da Moeda, 1991.

Gil Martínez, Francisco. "El 'arte de furtar'. Hacia una definición de corrupción en el siglo XVII". En La enfermedad de la Monarquía. Corrupción y anticorrupción en España y América (siglos XVI-XVIII), coordinado por Gil Martínez, Francisco - Villarreal Brasca, Amorina. Almería: Universidad de Almería. (En prensa).

Gil Martínez, Francisco - Villarreal Brasca, Amorina (coords.). La enfermedad de la Monarquía. Corrupción y anticorrupción en España y América (siglos XVIXVIII). Almería: Universidad de Almería. (En prensa).

Ponce Leiva, Pilar. "Séneca en los Andes. Neoestoicismo y crítica social en la Audiencia de Quito a fines del siglo XVII". Histórica. vol. XXXI, nº 2 (2007), 4368.

Ponce Leiva, Pilar - Andújar Castillo, Francisco (coords.). Mérito, venalidad y corrupción en España y América, siglos XVII y XVIII. Valencia: Albatros, 2016.

Rosenmüller, Christoph - Ruderer, Stephan. "Introducción. La nueva historia de la corrupción en América Latina". En "Dádivas, dones y dineros". Aportes a nueva historia de la corrupción en América Latina desde el imperio español a la modernidad, editado por Rosenmüller, Christoph - Ruderer, Stephan. Madrid: Iberoamericana - Vervuert, 2016, 7-25.

Villarreal Brasca, Amorina. "Ejemplaridad e imitación: conceptos y remedios para contrarrestar la corrupción de la Monarquía". Ponencia presentada en el Congreso Internacional Debates sobre la corrupción en el Mundo Ibérico, siglos XVIXVIII. Madrid, 8-9 de mayo de 2017. (En vías de publicación). 